\title{
Development of a New Silica Aerogel-Polypropylene Foam Composite as a Highly Flexible Thermal Insulation Material
}

\section{OPEN ACCESS}

Edited by:

Kazuyoshi Kanamori,

Kyoto University, Japan

Reviewed by:

Yuanqing $L i$,

Chongqing University, China

Guoqing $\mathrm{Zu}$,

Tongji University, China

*Correspondence:

Satoshi Yoda

s-yoda@aist.go.jp

Specialty section:

This article was submitted to

Polymeric and Composite Materials,

a section of the journal

Frontiers in Materials

Received: 02 March 2021

Accepted: 07 May 2021

Published: 26 May 2021

Citation:

Yoda S, Takeshita S, Ono T, Tada R and Ota $H$ (2021) Development of a

New Silica Aerogel-Polypropylene Foam Composite as a Highly Flexible

Thermal Insulation Material.

Front. Mater. 8:674846.

doi: 10.3389/fmats.2021.674846

\author{
Satoshi Yoda ${ }^{1 *}$, Satoru Takeshita ${ }^{1}$, Takumi Ono ${ }^{1}$, Ryosuke Tada ${ }^{2}$ and Hideo Ota ${ }^{2}$ \\ ${ }^{1}$ Research Institute for Chemical Process Technology, National Institute of Advanced Industrial Science and Technology (AIST), \\ Tsukuba, Japan, ${ }^{2}$ Inoac Technology Center, Hadano, Japan
}

A new flexible thermal insulation sheet, a composite of silica aerogel with polypropylene (PP) foam, has been developed. Even though a large volume ratio of silica aerogel (97\%) was included, the composite showed high flexibility. Thermal conductivity of the composite was $0.016 \mathrm{~W} /(\mathrm{m} \cdot \mathrm{K})$ at $298 \mathrm{~K}$, which is as low as silica aerogel monolith. Silica aerogel flaking, which has been a problem in practical applications, is very low in this composite due to skin layers of the polymer-foam composite. A supercritical drying process for rolled sheets of the material for large-scale production is also described. Simulations of extraction of 2-propanol from a silica alcogel revealed that rolled composite sheets with small spaces between the sheet composite are able to dry in a reasonable extraction time. These findings led to effective on production of this material on a pilot industrial scale.

\section{Keywords: silica aerogel, silica aerogel composite, polypropylene foam, thermal insulating material, flexible aeroge composite, simulation}

\section{INTRODUCTION}

Over the past several years, there has been significant interest in discovering new thermal insulating materials for a variety of applications. For example, energy conservation in the heating and air conditioning of residences and offices has been an important issue, and recently, thermal management of information and communication devices, vehicles (Haas and Walter, 2019), and electric appliances has become more important. Due to the limited amount of space for thermal insulation and the complex shapes required, flexible and thin high performance materials are needed. Vacuum insulation panels (VIP) provide the best insulation performance, but are not suitable for many applications due to a lack of flexibility and no workability. A flexible, high-performance, thermal insulating sheet which can easily be cut, drilled or pasted would be quite useful.

Silica aerogels have been identified as excellent candidates for high-performance insulators (Aegerter et al., 2011). Due to their ultra-low density and the "Knudsen effect" in mesoporous structures (Forest et al., 2015) (Jelle et al., 2019), silica aerogels demonstrate very low thermal conductivity $(0.01-0.02 \mathrm{~W} /(\mathrm{m} \bullet \mathrm{K})$ at room temperature). The thermal insulating performance does not deteriorate over time, because the low thermal conductivity depends on the structure of the material, not on the presence of a vacuum or a gas with low thermal conductivity. This is of great advantage in small/thin thermal insulation materials. However, the fragility of silica aerogels has thus far proven a critical barrier for their use in flexible insulating materials. 
A variety of silica aerogel composites have been investigated to overcome this barrier. A combination of silica aerogel and fibers has been shown to be effective in enhancing mechanical strength and improve handling. Inorganic (glass, silica, alumina and other oxides, carbon) and organic (natural and artificial polymers) fibers have been employed as reinforcement materials (Linhares et al., 2019). Composites with nanofibers such as cellulose (Cai et al., 2012) and polyvinylidene fluoride (Wu et al., 2013) demonstrated very high flexibility. Combination of silica aerogels and nonwoven sheets or fiber felts has been successfully marketed as industrial products from Aspen Aerogels, Cabot Corporation and other suppliers (Miros et al., 2017) and have been applied as thermal insulation for pipelines, buildings, residences and in protective clothing. When the fibric compound content is low, the thermal conductivity of these materials is close to that of silica aerogels $(\sim 0.02 \mathrm{~W} /(\mathrm{m} \bullet \mathrm{K})$. However, silica aerogel flaking from the composite is essentially unavoidable and conspicuous, since silica aerogel structure is so fragile. These materials must therefore be avoided in applications where dust is unacceptable.

Different types of silica aerogel-polymer composites, in which silica aerogels were used as fillers in polymer matrix, have been investigated (Guzel Kaya and Deveci, 2020). Epoxy resin (Kim et al., 2015), polyurethane (Cho et al., 2019), polyethylene (Zulkipli and Romli, 2018) and polyimide (Kim et al., 2014) have also been investigated. Silica aerogel-thermosetting polymer composites produced via chemical reaction and phase separation have been produced for high temperature use. For example, a polymimide-silica aerogel composite was developed with thermal conductivity of $0.022 \mathrm{~W} /(\mathrm{m} \bullet \mathrm{K}$ ) (Fan et al., 2019) and $\mathrm{Yu}$ et al. produced phenol-formaldehyde resin composite with a thermal conductivity of $0.028 \mathrm{~W} /(\mathrm{m} \cdot \mathrm{K})$ (Yu et al., 2018). All of these composites have better mechanical properties and workability than simple silica aerogels, and are likely to show little flaking. However, the silica aerogel content in these composites is not high, probably because there are many technical difficulties in mixing low density silica aerogels with polymers. Furthermore, the thermal conductivity of these materials is $\sim 0.03 \mathrm{~W} /(\mathrm{m} \bullet \mathrm{K})$ at the lowest, which is comparable to conventional, cheap thermal insulators. Thus, there is little advantage in applying these silica aerogel composites as commercial insulating materials.

Combining a polymer foam with silica aerogels is an alternative approach to achieve both high silica aerogel content and to avoid flaking. Inoue et al. reported the development of a silica aerogel-polyurethane foam composite (Inoue and Yamanobe, 2013). In their work, a silica sol was introduced into highly porous polyurethane foam $\left(0.014 \mathrm{~g} / \mathrm{cm}^{3}\right)$, and a silica alcogel was formed inside of the cellular structure. Then, the composite was dried in supercritical carbon dioxide $\left(\mathrm{CO}_{2}\right)$. Thermal conductivity of the composite is around $0.02 \mathrm{~W} /$ $(\mathrm{m} \bullet \mathrm{K})$. They reported that the aerogel composite did not fracture during compression testing, but did not mention the flexibility of the material. Zhao et al. produced a silica aerogelpolyisocyanurate rigid foam composite via reactive foaming with a granular silica aerogel (Zhao et al., 2014). The composite shows a minimum thermal conductivity of $0.0233 \mathrm{~W} /(\mathrm{m} \bullet \mathrm{K})$. The compressive strength was better than that of polyisocyanurate rigid foam without the silica aerogel. Ease of handling and workability may be the same as polyisocyanurate; however, flexibility and aerogel flaking were not mentioned in their work.

We have developed a new, highly flexible, high performance thermal insulation material with a low degree of silica aerogel flaking. Our strategy is similar to that of Inoue's work, i.e., combining a soft polymer foam having open pores with a silica aerogel prepared inside of the foam, followed by supercritical drying. We previously reported the development of combinations of silica aerogels and various polymer foams including polyurethane, melamine, and polypropylene (PP). These compounds show thermal conductivity as low as silica aerogel monolith (Yoda and Furuya, 2012). Herein, we follow up on the development of our PP foam composite and present its path to commercial production. Thermal conductivity data as well as the mechanical properties of the composite have been added. Since the silica alcogel and polypropylene composite is flexible, the supercritical drying process for the rolled composite is also presented, which is effective strategy for decreasing the production cost of the material on a commercial scale.

\section{EXPERIMENTAL}

\section{Preparation of Polymer Foam-Silica Aerogel Composites}

Open pore-type polymer foams were employed as the matrices. Table 1 summarizes the polymer foams used in this work. Figure $\mathbf{1}$ is a scanning electron micrograph (SEM) image of PP foam with skin layers. It was difficult to maintain uniformity in the thickness of the foams. All of the polymer foams were confirmed to resist swelling in supercritical $\mathrm{CO}_{2}$ under the drying conditions employed.

Tetramethoxysilane (TMOS, Tokyo Kasei Co., Ltd. and Shinetsu Kagaku Co,. Ltd.), methanol (Wako, 99.9\%), ammonia water (Wako), and $\mathrm{CO}_{2}$ (Showa Tansan, 99.9\%) were used without further purification. Silica sols were prepared by mixing TMOS, water, methanol, and ammonia. The typical molar ratio was 1:4:7.2:0.001, respectively, based on our previous optimization of silica aerogel with a density of $0.16 \mathrm{~g} / \mathrm{cm}^{3}$. The sol was introduced into the polymer foams and left there until gelation occurred. These sol-gel processes were conducted at room temperature. After aging at $333 \mathrm{~K}$ for 2 days and solvent exchange with methanol at room temperature, hydrophobization of surface silanols using 1,1,1,3,3,3hexamethyldisilazane (HMDS, Wako, 96\%) as a silane coupling agent was conducted. The silica wet gel was soaked in $10 \mathrm{wt} \%$ of methnolic HMDS and refluxed at $333 \mathrm{~K}$. The amount of HMDS was calculated to be an excess for the estimated number of surface silanol groups in the silica wet gel. Then, the polymer foam and silica alcogel composite was placed in an autoclave with a small amount of methanol or 2propanol and dried in supercritical $\mathrm{CO}_{2}$ at $20 \mathrm{MPa}$ and $353 \mathrm{~K}$. The details of the preparation are similar to those described in our previous paper (Yoda et al., 2004). For evaluation of mechanical properties, polymer foams were cut into prescribed size $(70 \times 20$ 
TABLE 1 | List of polymer foams in this work.

\begin{tabular}{|c|c|c|c|c|c|}
\hline Sample name & $\begin{array}{c}\text { Supplier/Product } \\
\text { name }\end{array}$ & $\begin{array}{l}\text { Density } \\
\left(\mathrm{kg} / \mathrm{m}^{3}\right)\end{array}$ & $\begin{array}{l}\text { Pore size } \\
(\mu \mathrm{m})\end{array}$ & $\begin{array}{l}\text { Porosity } \\
\text { (\%) }\end{array}$ & $\begin{array}{c}\text { Thickness } \\
\text { (mm) }\end{array}$ \\
\hline Polypropylene (PP) foam with skin layers & Inoac/Folec ${ }^{\circledR}$ & 60 & $150-200$ & 93 & 1.8 \\
\hline Polypropylene (PP) foam without skin layers & Inoac/Folec ${ }^{\circledR}$ & 60 & $150-200$ & 93 & 1 \\
\hline Polyurethane foam (ester type) & $\begin{array}{l}\text { BridgeStone/Everlight }{ }^{\circledR} \\
\text { HR-50 }\end{array}$ & 39 & $500-1,000$ & 97 & 5 \\
\hline Melamine foam & Strider co. Ltd & 9.5 & $500-$ & 94 & 5 \\
\hline
\end{tabular}

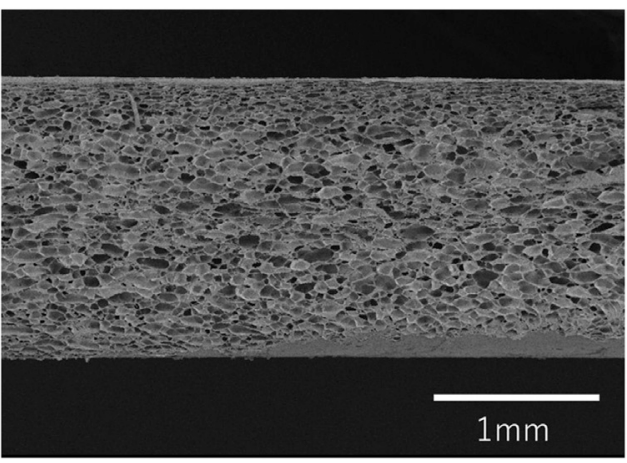

FIGURE 1 | SEM image of PP foam with skin layers.

and $20 \times 20 \mathrm{~mm}$ ) and placed in stacks of a few sheets of approximately the same thickness (10 and $5 \mathrm{~mm}$ ), and the solgel process was conducted after they were immersed in the silica sol.

\section{Evaluation}

Thermal conductivity was evaluated via the heat flow meter method (ASTM C518). Analyses were conducted with a heat flux meter (Eko Instruments, HC-074) at $298 \mathrm{~K}$, with the lower heat plate at $288 \mathrm{~K}$ and the upper heat plate at $308 \mathrm{~K}$. For thin samples, the sample was located between two base sheets (silicone sponge), of which thickness and thermal conductivity were known. Sample thermal conductivity $\lambda s$ was calculated from measured thermal conductivity $\lambda_{s+2 b}$ and that of base sheet $\lambda_{b}$ with the following equation:

$$
\lambda_{s}=\frac{t_{s}}{t_{s}+2 t_{b}} \cdot \frac{\lambda_{s+2 b} \cdot \lambda_{b}}{\lambda_{b}-\left(\frac{2 t_{b}}{t_{s}+2 t_{b}}\right) \cdot \lambda_{s+2 b}}
$$

where $t_{\mathrm{s}}$ and $t_{b}$ are the thicknesses of sample and sponge sheet, respectively, (Yoda, 2021).

The microstructure of the materials was observed via scanning electron microscopy (SEM, Hitachi S-4800) after coating with Pt$\mathrm{Pd}$ by ion spattering. Compression tests for test pieces $(20 \times 20 \times$ $10 \mathrm{~mm}$ ) were performed on an Autograph AG5000A with a displacement speed of $1 \mathrm{~mm} / \mathrm{min}$. The compression tests were repeated three times for each type of samples. Compressive stress $\sigma_{c}$ and compressive strain $\varepsilon_{c}$ were calculated with the following equations:

$$
\begin{gathered}
\sigma_{c}=\frac{F_{c}}{A} \\
\varepsilon_{c}=\frac{d-d_{0}}{d_{0}}
\end{gathered}
$$

where $F_{c}$ is load applied, $A$ is area of test piece, $d_{0}$ and $d$ were thickness of test piece before and after compression, respectively.

Three-point bending tests using test pieces $(70 \times 20 \times 10 \mathrm{~mm})$ were performed on a Strograph R3 (Toyo Seiki Co., Ltd.) with a displacement speed of $1 \mathrm{~mm} / \mathrm{min}$. Since PP foam was thinner than other polymer foams, the PP foam-silica aerogel measurements were conducted using samples prepared using five PP foam sheets as described in 2.1. Bending stress $\sigma_{b}$ and bending strain $\varepsilon_{b}$ were calculated with the following equations:

$$
\begin{aligned}
\sigma_{b} & =\frac{3 F_{b} L}{2 b d} \\
\varepsilon_{b} & =\frac{6 D d}{L^{2}}
\end{aligned}
$$

where $F_{b}$ is load at a given point, $L$ is support span, $D$ is deflection of the center of the test piece, $b$ and $d$ were width and thickness of test piece, respectively.

Weight loss by removal of silica after continuous bending and rubbing tests (1,200 times/10 min) was evaluated using a dusting Scott flex abrasion tester (Toyo Seiki Co., Ltd.).

\section{Simulation of Supercritical Drying Process}

Extraction of 2-propanol from the silica alcogel during the supercritical drying process was simulated for optimization of temperature, pressure, and extraction time. In the experiment, the PP foam-silica alcogel composite rolled sheet was set in a highpressure vessel and dried in supercritical $\mathrm{CO}_{2}$. According to the experimental settings, the 2-dimensional model of the silica aerogel was assumed to be as shown in Figure 2.

In the simulation, the effect of the PP foam matrix is assumed to be negligible for simplicity, since the PP content is less than $5 \mathrm{vol} \%$. The silica aerogel was considered as a packed bed with $95 \%$ of porosity and $50 \mathrm{~nm}$ of pore diameter, which was modeled by permeability $\alpha$ and inertial loss coefficient $C_{2}$ :

$$
\begin{gathered}
\alpha=\frac{D_{p}^{2}}{150} \frac{\varepsilon^{3}}{(1-\varepsilon)^{2}} \\
C_{2}=\frac{3.5}{D_{p}} \frac{(1-\varepsilon)}{\varepsilon^{3}}
\end{gathered}
$$






FIGURE 2 | Simulation model for supercritical drying.

TABLE 2 | Operating conditions and assumed parameters for the simulation.

\begin{tabular}{|c|c|c|c|c|c|}
\hline \multicolumn{2}{|c|}{ Operating condition } & \multicolumn{2}{|c|}{$\mathrm{CO}_{2}$} & \multicolumn{2}{|c|}{ 2-Propanol } \\
\hline Pressure (MPa) & Temperature $(\mathrm{K})$ & Density $\left(\mathrm{kg} / \mathrm{m}^{3}\right)$ & Viscosity ( $\mu \mathrm{Pa} \cdot \mathbf{s})$ & Density $\left(\mathrm{kg} / \mathrm{m}^{3}\right)$ & Viscosity ( $\mu \mathrm{Pa} \cdot \mathbf{s})$ \\
\hline 20 & 313 & 841 & 78.5 & 791 & 1,590 \\
\hline 14 & 353 & 388 & 30.0 & 750 & 634 \\
\hline
\end{tabular}

TABLE 3 | Properties of polymer foam-silica aerogel composites.

\begin{tabular}{|c|c|c|c|c|c|}
\hline \multirow[t]{2}{*}{ No } & \multirow[t]{2}{*}{ Sample name } & \multirow[t]{2}{*}{ Bending properties } & \multirow[t]{2}{*}{ Density $\left(\mathrm{kg} / \mathrm{m}^{3}\right)$} & \multicolumn{2}{|c|}{ Thermal conductivity $(\mathrm{W}(\mathrm{m} \bullet \mathrm{K}))$} \\
\hline & & & & Composite & Matrix foam \\
\hline 1 & PP foam with skin layers & Flexible, foldable & 170 & 0.016 & 0.030 \\
\hline 2 & PP foam without skin layers & Flexible, foldable & 167 & 0.017 & 0.029 \\
\hline $3^{a}$ & Polyurethane foam (ester type) & Foldable, plastically deformed & 143 & $0.022^{b}$ & 0.035 \\
\hline $4^{a}$ & Melamine foam & Plastically deformed & 131 & $0.020^{b}$ & 0.036 \\
\hline $5^{a}$ & Silica aerogel & Fragile & 166 & 0.018 & \\
\hline
\end{tabular}

${ }^{a}$ Data from reference (Yoda and Furuya, 2012)

${ }^{b}$ Measured at $293 \mathrm{~K}$.

These equations have been evaluated from the Ergun equation and Blake-Kozeny equations. Here, $\varepsilon$ is porosity and $D_{\mathrm{p}}$ is Average particle diameter (Bortolin et al., 2015).

The simulated operating conditions and physical properties of substances are listed in Table 2 . These values were found in the fluid database (JMSE, 1983) or predicted by correlation. The concentration distribution of 2-propanol in the model silica gel was calculated for each extracting condition by ANSYS/Fluent v18.0, based on the Navier-Stokes equation and the diffusion equation for both $\mathrm{CO}_{2}$ and 2-propanol.

\section{RESULTS AND DISCUSSION}

\section{Properties and Microstructures of Polymer Foam-Silica Aerogel Composite}

Table 3 summarizes the properties of the polymer foam-silica aerogel composites. None of the composites were fragile, and some composites were flexible. The density of the products was almost the same as that of the same silica aerogels prepared without polymer foam. The thermal conductivity of the Polymer foam-silica aerogel was $0.016-0.022 \mathrm{~W} /(\mathrm{m} \bullet \mathrm{K})$ at $298 \mathrm{~K}$ under atmospheric pressure, which is as low as that of the parent silica aerogel. Thermal conductivity measurements of the PP foam-silica aerogel composite using a large size sample by the guarded hot plate method at the Japanese Testing Center for Construction Materials (JTCCM) provided the same thermal conductivity result.

The PP-foam silica aerogel can almost be folded and shows resiliency when bent, as shown in Figure 3. The PP-foam had good workability, and is able to be easily cut with scissors or a knife. Polyurethane foam-silica aerogels show similar workability, but poor resiliency when bent.

SEM images of the foams and aerogel composites are shown in Figure 4A-D and those of the silica aerogel prepared in the same conditions are shown in Figure 4E. There were very small spaces $(\sim 1 \mu \mathrm{m})$ between the polymer foam network and the silica aerogel, probably due to the silica wet gel crosslinking through the pore structure upon formation, and then shrinking slightly during aging and drying.

Figure 5A shows stress-strain curves upon a compression testing of samples in this work. The properties of polymer foam-silica aerogels upon compression testing were close to those of the pure silica aerogel. 

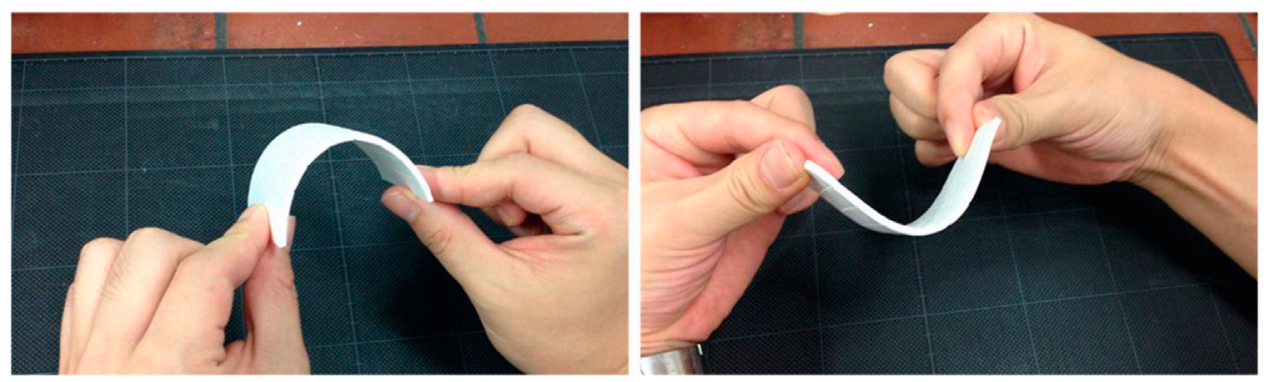

FIGURE 3 | Bending demonstration of PP foam-silica aerogel composite.

Differences in each polymer foams may reflect the difference in interfacial space between the silica aerogels and the polymer foam matrices. Figure 5B shows stress-strain curves upon 3-point bending tests of the PP foam with skin layer-silica aerogel composite, silica aerogel and PP foam. Despite the extremely high volume content of silica aerogel in the composite, the bending strengths were much higher than that of the pure silica aerogel. That is, reinforcement by the highly porous materials was effective.

\section{Flaking of Silica Aerogel From Polymer Foam Composites}

The flaking of silica aerogels from the composites was evaluated. Such flaking can cause a variety of problems for products containing silica aerogel composites, and has been a barrier for expanding their use. Table 4 shows the results of bending and rubbing tests for silica aerogel flaking. A load was usually employed on the sample in the initial stage of the test. Loading the PP foam-silica aerogel produced very little weight loss. However, both polyurethane foam and melamine foam composite could not physically withstand and started flaking before the test using the same load as that for the PP foam. These two samples thus had to be tested under zero load. Even under zero load, the melamine foam composite was broken after a few movements.

The PP foam with skin layers and silica aerogel composite showed high flexibility and low flaking. Due to limited choices of open-pore-type polymer foams with extremely high porosity (and also limited publishable information on their structural properties form the production companies), a systematic investigation of effect of pore size, pore size distribution and interfacial interaction is difficult. However, the high flexibility and low flaking of the PP foam-silica aerogel is probably due to the high flexibility of the PP foam matrix and the relatively high dispersion of the silica aerogels in the PP foam. As shown in Table 1, the PP foam has the smallest pore size of the polymers in this work $(100-200 \mu \mathrm{m})$ and the pores are cellular in nature (unlike the reticulate structure of the melamine foam). Silica aerogels in the pores of a PP foam would be more independent than that in polyurethane foam and in melamine foam. Small, partial breaks were observed in the PP foam-silica aerogels when bent, but the breaks were limited to a localized part of the dispersed aerogel. In addition, the skin layers prevented flaking of the partially broken silica aerogel. This result indicates that providing a higher dispersion of silica aerogel in flexible materials is a promising approach for developing highly flexible and high-performance thermal insulating materials.

\section{Simulation on Supercritical Drying of a Rolled Sheet}

Since the PP foam-silica alcogel composite has some flexibility, the supercritical drying process of a rolled sheet (Figure 6) was investigated. Extraction of alcohol is known to be diffusioncontrolled inside silica alcogels (Özbakir and Erkey, 2015). For large-scale production with a space-saving rolled shape, the gap between the sheets should be small. However, such setting should require the long extraction time and understanding the effect of extraction conditions for drying time is important for commercialization. The extraction time of 2-propanol by supercritical $\mathrm{CO}_{2}$ from a model strip in rolled silica alcogel was simulated.

Table 5 summarizes the simulation conditions and simulated drying times of silica aerogel by $\mathrm{CO}_{2}$ supercritical drying, where the final 2-propanol mass fraction is under $3.5 \times 10^{-6}$. Figure 7 represents a graphical summary of typical extraction of 2propanol in a $\mathrm{CO}_{2}$ system. These figures correspond to the simulation model in Figure 2 although the aspect ratio on print is different. The solid-line square shown in the figure corresponds to the silica alcogel. The distance from the center of the roll to the sheet was $87.45 \mathrm{~mm}$, which was assumed the outermost side of the roll. The red color indicates 2-propanol, and the blue color indicates $\mathrm{CO}_{2}$. At a condition for Figure 7A, extraction began 1,800 s after flow initiation, and then 2-propanol in the silica gel was replaced by $\mathrm{CO}_{2}$ gradually. All the 2-propanol was removed from the system by $10,800 \mathrm{~s}$ under these conditions. High-temperature and lowpressure conditions were effective on shortening the drying time probably because of low viscosity and high diffusion in silica as shown in Figure 7B,C. A large flow rate of $\mathrm{CO}_{2}$ was also effective in shortening the drying time as shown in Figure 7D. Due to surface 2-propanol on the silica gel is rapidly replaced with $\mathrm{CO}_{2}$, the concentration difference in the silica gel (i.e., the driving force of drying) becomes large. However, it should be noted that even if the $\mathrm{CO}_{2}$ flow rate is increased 10 times as shown in (a) and (d) of Table 5, the drying time is only reduced by about $2 / 3$. Since the gel size is the 
A PP foam with skin layer
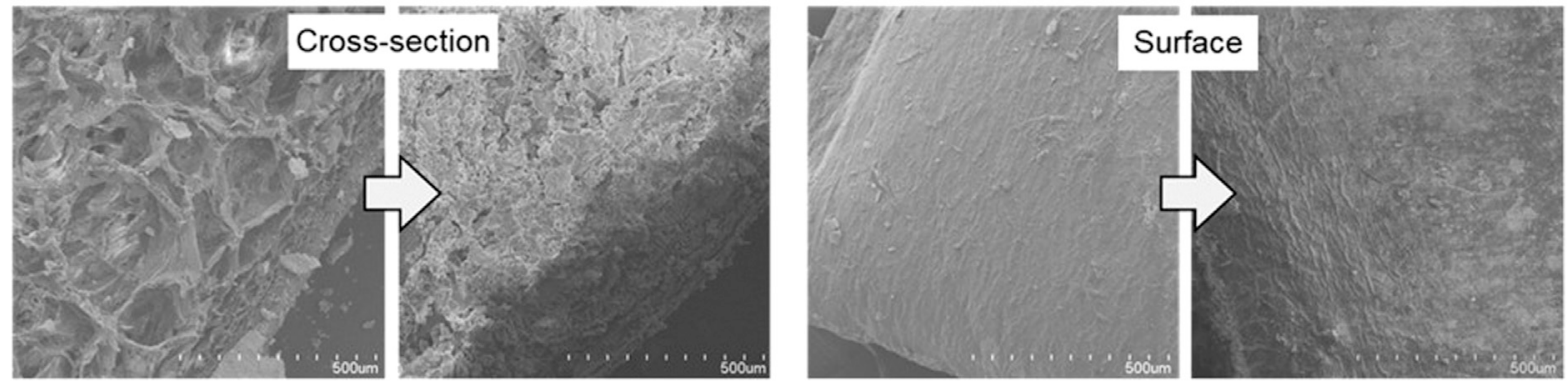

B PP foam without skin layer
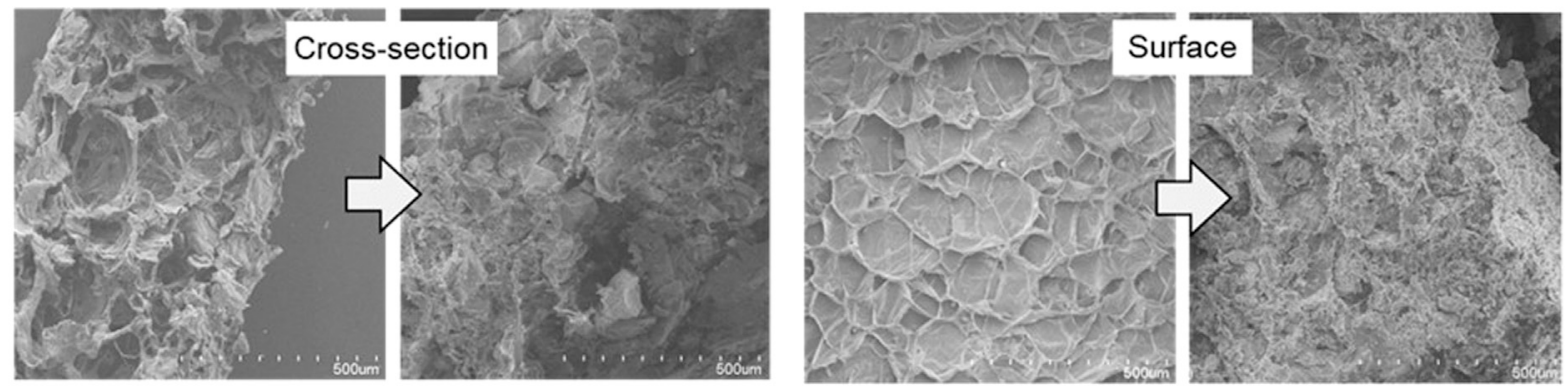

C Polyurethane foam (Ref. (Yoda, 2012))

\section{Melamine foam (Ref. (Yoda, 2012))}
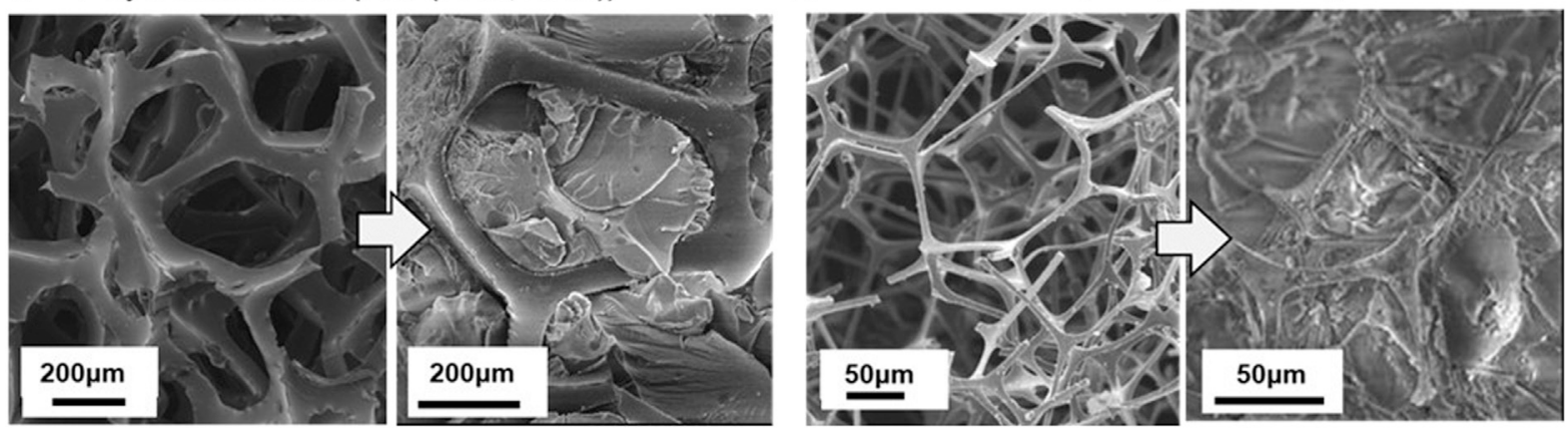

\section{E Silica Aerogel (Ref. (Yoda, 2012))}

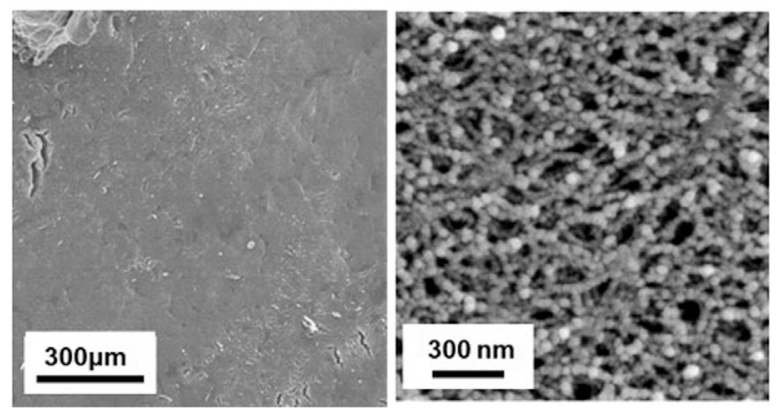

FIGURE 4 | SEM images of polymer foams (left) and their silica aerogel composites (right). (A) PP foam with skin layers, (B) PP foam without skin layers, (C) polyurethane foam, and (D) melamine foam and (E) silica aerogel prepared in the same conditions (low mag. (left) and close up (right)).

dominant factor for extraction in diffusion-controlled processes, having a large flow rate of $\mathrm{CO}_{2}$ was less effective than other factors. These results show that a supercritical drying process for a large-scale roll of thin sheet material can be completed within a practical time, so long as a small gap is kept between the layers of the rolled sheet.

\section{CONCLUDING REMARKS}

A new, flexible, thermal-insulating sheet of PP foam-silica aerogel composite was developed. The sheet shows good flexibility and low thermal conductivity $(0.016 \mathrm{~W} /(\mathrm{m} \bullet \mathrm{K}))$, with mechanical performance superior to other polymer- 

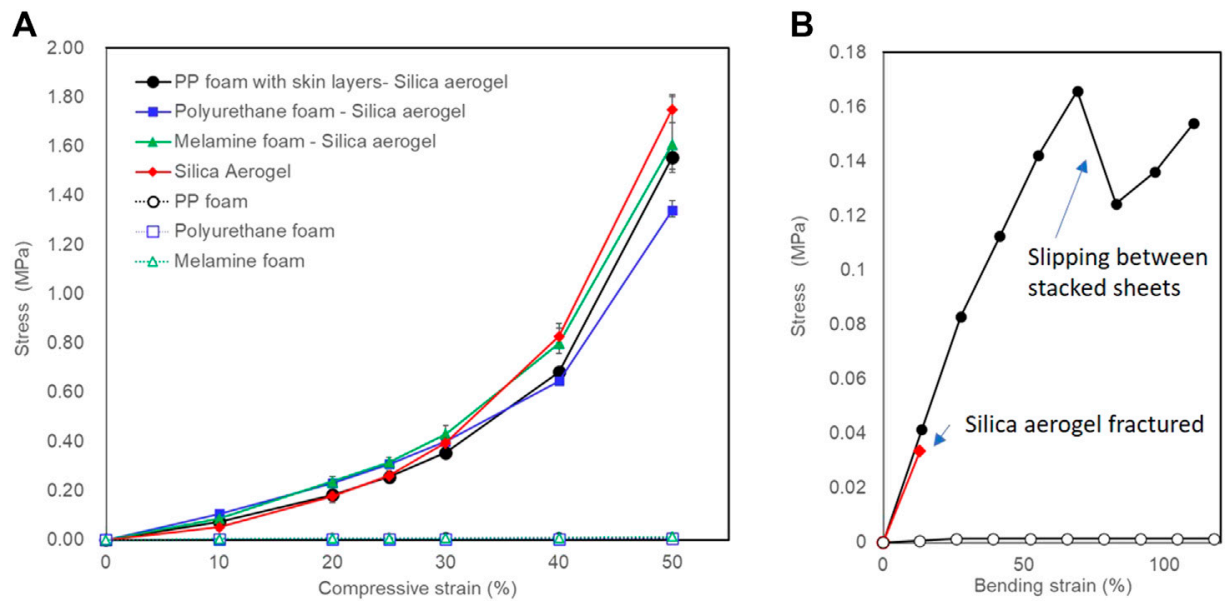

FIGURE 5 | Stress strain curves upon (A) compression testing of samples in this work and (B) 3-point bending test for PP foam with skin layer-aerogel composite, silica aerogel and PP foam.

TABLE 4 | Results of the bending and rubbing tests for silica aerogel flaking.

\begin{tabular}{|c|c|c|c|c|c|}
\hline \multirow[t]{2}{*}{ Sample (matrix) } & \multirow[t]{2}{*}{ Run no } & \multirow[t]{2}{*}{ Load on sample (g) } & \multicolumn{3}{|c|}{ Weight loss after bending/rubbing test } \\
\hline & & & $\begin{array}{c}\text { Weight } \\
\text { before test (g) }\end{array}$ & $\begin{array}{l}\text { Weight } \\
\text { after test (g) }\end{array}$ & Weight loss (wt\%) \\
\hline \multirow[t]{2}{*}{ PP-foam with skin layers } & 1 & 200 & 0.239 & 0.234 & 1.7 \\
\hline & 2 & 200 & 0.252 & 0.246 & 2.4 \\
\hline \multirow[t]{2}{*}{ PP-foam without skin layers } & 1 & 200 & 0.126 & 0.114 & 9.5 \\
\hline & 2 & 200 & 0.127 & 0.114 & 9.9 \\
\hline \multirow[t]{2}{*}{ Polyurethane foam } & 1 & 0 & 0.301 & 0.228 & 24.0 \\
\hline & 2 & 0 & 0.390 & 0.284 & 27.0 \\
\hline Melamine foam & 1 & 0 & & en after a few $m$ & \\
\hline
\end{tabular}

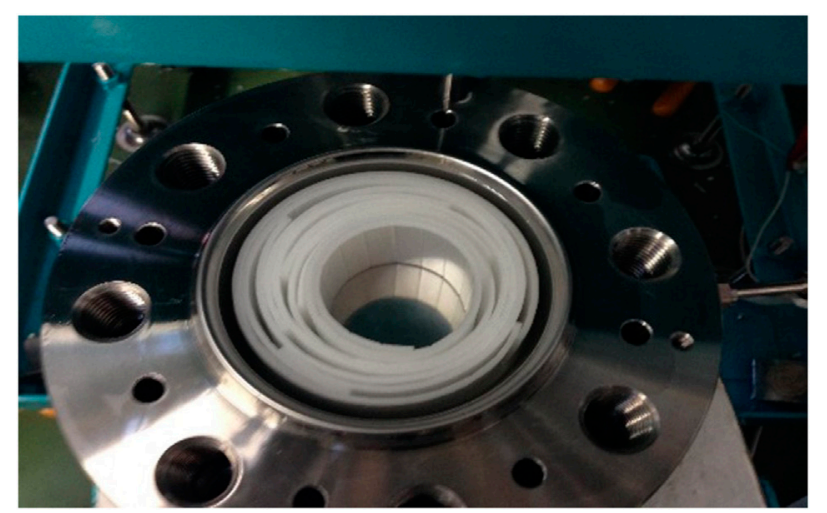

FIGURE 6 | Supercritically dried PP foam-silica aerogel composite rolled sheet (laboratory scale).

aerogel composites. Silica aerogel flaking from the composite, a barrier for a variety of applications, was very low for the composite, probably due to the skin layers of the PP foam matrix. Since the composite is flexible, a supercritical drying process was developed for a rolled composite sheet. Simulations

TABLE 5 | Simulated drying time of silica aerogel by $\mathrm{CO}_{2}$ supercritical drying.

case

(a) 20

(b) 20

(c) 14

(d)

of extraction time were conducted on rolls having a small gap $(0.05 \mathrm{~mm})$ between the sheet layers of the roll. The extraction was confirmed to complete in 1-2 h, which makes a large-scale production process practical.

These results have now been applied in a pilot-scale production process using low cost silicate, and a rolled sheets $400 \mathrm{~mm} \times 30 \mathrm{~m}$ have successfully been produced. The thermal conductivity of the large-scale product was confirmed by a guarded hot plate method, and the same thermal conductivity $(0.016 \mathrm{~W} /(\mathrm{m} \cdot \mathrm{K}))$ was observed. We believe the material will prove usefulness for a variety of thermal insulation applications, and it is on track to develop a large-scale production process. 


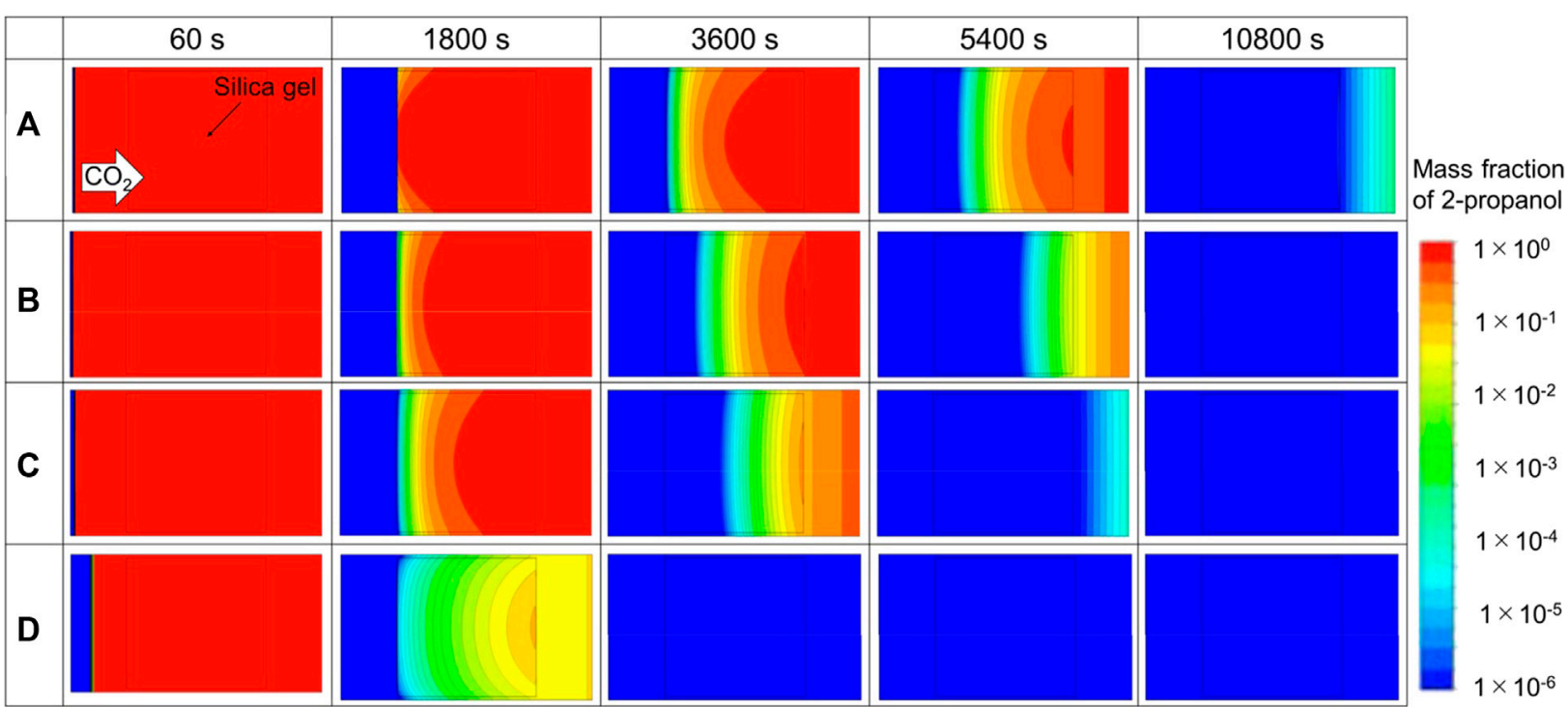

FIGURE 7 | Concentration profile of 2-propanol within the high-pressure vessel with silica alcogel. (A-D) correspond to case A-D in Table $\mathbf{5}$

\section{DATA AVAILABILITY STATEMENT}

The raw data supporting the conclusions of this article are available from the corresponding author, SY, upon reasonable request.

\section{AUTHOR CONTRIBUTIONS}

SY: Preparation of the materials, Measurements of thermal conductivity and mechanical strength ST: Supercritical drying, SEM observations, TO: Simulations on supercritical drying

\section{REFERENCES}

Aegerter, M. A., Leventis, N., and Koebel, M. M. (2011). Aerogels Handbook. New York: Springer

Bortolin, S., Toninelli, P., Maggiolo, D., Guarnieri, M., and Del Col, D. (2015). CFD Study on Electrolyte Distribution in Redox Flow Batteries. J. Phys. Conf. Ser. 655, 012049. doi:10.1088/1742-6596/655/1/012049

Cai, J., Liu, S., Feng, J., Kimura, S., Wada, M., Kuga, S., et al. (2012). Cellulose-Silica Nanocomposite Aerogels by In Situ Formation of Silica in Cellulose Gel. Angew. Chem. Int. Ed. 51 (9), 2076-2079. doi:10.1002/anie.201105730

Cho, J., Jang, H. G., Kim, S. Y., and Yang, B. (2019). Flexible and Coatable Insulating Silica Aerogel/polyurethane Composites via Soft Segment Control. Composites Sci. Tech. 171, 244-251. doi:10.1016/j.compscitech. 2018.12.027

Fan, W., Zhang, X., Zhang, Y., Zhang, Y., and Liu, T. (2019). Lightweight, strong, and Super-thermal Insulating Polyimide Composite Aerogels under High Temperature. Composites Sci. Tech. 173, 47-52. doi:10.1016/j.compscitech. 2019.01.025

Forest, C., Chaumont, P., Cassagnau, P., Swoboda, B., and Sonntag, P. (2015). Polymer Nano-Foams for Insulating Applications Prepared from CO2 Foaming. Prog. Polym. Sci. 41, 122-145. doi:10.1016/j.progpolymsci.2014. 07.001
RT: Simulations on supercritical drying, Process design for commercial scale production HO: Process design for commercial scale production.

\section{FUNDING}

This work is based on results obtained from a project (P12004) commissioned by the New Energy and Industrial Technology Development Organization (NEDO), Japan. The authors appreciate C. Xiao and H. Sato for their assistance on this work.

Guzel Kaya, G., and Deveci, H. (2020). Synergistic Effects of Silica Aerogels/ xerogels on Properties of Polymer Composites: A Review. J. Ind. Eng. Chem. 89, 13-27. doi:10.1016/j.jiec.2020.05.019

Haas, S., and Walter, M. (2019). Current Status and Need for thermal Insulation in Electric Cars to Reduce Heating and Cooling Capacity. in Applied Research Conference 2019 at. OTH Regensburg. https://www.researchgate.net/publication/ 334307499_Current_status_and_need_for_thermal_insulation_in_electric_cars_ to_reduce_heating_and_cooling_capacity\#fullTextFileContent

Inoue, N., and Yamanobe, T. (2013). Preparation and Aging of Polyurethane Foams Filled with Silica Aerogels. Kobunshi Ronbunshu 70 (4), 123-128. doi:10. 1295/koron.70.123

Jelle, B. P., Mofid, S. A., Gao, T., Grandcolas, M., Sletnes, M., and Sagvolden, E. (2019). Nano Insulation Materials Exploiting the Knudsen Effect. IOP Conf. Ser. Mater. Sci. Eng. 634, 012003. doi:10.1088/1757-899x/634/1/012003

Kim, H. M., Kim, H. S., Kim, S. Y., and Youn, J. R. (2015). Silica Aerogel/epoxy Composites with Preserved Aerogel Pores and Low thermal Conductivity. e-Polymers 15 (2), 111-117. doi:10.1515/epoly-2014-0165

Kim, S. Y., Noh, Y. J., Lim, J., and You, N.-H. (2014). Silica Aerogel/polyimide Composites with Preserved Aerogel Pores Using Multi-step Curing. Macromol. Res. 22 (1), 108-111. doi:10.1007/s13233-014-2006-0

Linhares, T., Pessoa de Amorim, M. T., and Durães, L. (2019). Silica Aerogel Composites with Embedded Fibres: a Review on Their Preparation, Properties and Applications. J. Mater. Chem. A. 7 (40), 22768-22802. doi:10.1039/C9TA04811A 
Miros, A., Psiuk, B., and Szpikowska-Sroka, B. (2017). Aerogel Insulation Materials for Industrial Installation: Properties and Structure of New Factory-Made Products. J. Sol-gel. Sci. Technol. 84, 496-506. doi:10.1007/s10971-017-4539-0

Ozbakir, Y., and Erkey, C. (2015). Experimental and Theoretical Investigation of Supercritical Drying of Silica Alcogels. J. Supercrit. Fluids 98, 153-166. doi:10. 1016/j.supflu.2014.12.001

The Japan Society of Mechancal Engineers (JSME) (1983). in JSME Data Book: Thermophysical Properties of Fluids (Tokyo: JMSE).

Wu, H., Chen, Y., Chen, Q., Ding, Y., Zhou, X., and Gao, H. (2013). Synthesis of Flexible Aerogel Composites Reinforced with Electrospun Nanofibers and Microparticles for Thermal Insulation. J. Nanomater. 2013, 1-8. doi:10. $1155 / 2013 / 375093$

Yoda, S., and Furuya, T. (2012). Preparation of Polymer Foam-Silica Aerogel Composites and its Evaluation as Thermal Insulator. Seikei kako 24 (3), 154-158. doi:10.4325/seikeikakou.24.154

Yoda, S., Takebayashi, Y., Sugeta, T., and Otake, K. (2004). Platinum-silica Aerogels via Supercritical Drying and Impregnation. J. Non-Crystalline Sol. 350, 320-325. doi:10.1016/j.jnoncrysol.2004.06.026

Yu, Z.-L., Yang, N., Apostolopoulou-Kalkavoura, V., Qin, B., Ma, Z.-Y., Xing, W.Y., et al. (2018). Fire-Retardant and Thermally Insulating Phenolic-Silica Aerogels. Angew. Chem. Int. Ed. 57 (17), 4538-4542. doi:10.1002/anie. 201711717
Zhao, C. Y., Yan, Y., Hu, Z. H., Li, L. P., and Fan, X. Z. (2014). Preparation and Performance Characterization of Polyisocyanurate (PIR)/silica Aerogel Composite Rigid Foam Insulation Materials. Construction Building Mater. 93, 309-316. doi:10.3963/j.issn.1671-4431.2014.08.004

Zulkipli, A. H., and Romli, A. Z. (2018). Thermal Characterization of Low Density Polyethylene (LDPE)/rice Husk Ash and rice Husk Ash Derived Silica Aerogel Composites. AIP Conf. Proc. 1985 (1), 030011. doi:10.1063/1.5047169

Conflict of Interest: Authors RT and HO were employed by the company Inoac Technology Center.

The remaining authors declare that the research was conducted in the absence of any commercial or financial relationships that could be construed as a potential conflict of interest.

Copyright (C) 2021 Yoda, Takeshita, Ono, Tada and Ota. This is an open-access article distributed under the terms of the Creative Commons Attribution License (CC $B Y$ ). The use, distribution or reproduction in other forums is permitted, provided the original author(s) and the copyright owner(s) are credited and that the original publication in this journal is cited, in accordance with accepted academic practice. No use, distribution or reproduction is permitted which does not comply with these terms. 